\title{
The Users View of Enterprise Integration and the Enterprise Process Architecture
}

\author{
Juan Carlos Mendez Barreiro \\ ADN INTERNACIONAL, S.A. DE C.V., Mexico, jcmendez@adn.com.mx
}

\begin{abstract}
The paper describes an architecture and methodology developed for the introduction of enterprise integration into the enterprises in Mexico. Starting from the experience gained as a management consultant a concept has been developed that allows the user to understand, evaluate and implement integration technology.
\end{abstract}

\section{INTRODUCTION}

Most of the companies around Mexico searching for adequate technology (including tools and methodologies) to be used in their company have to see (preferable on paper) the structure and the related knowledge of their processes. This information is needed to support a number of decisions to be made in the course of acquiring and implementing such technology. Therefore, any supporting architecture or methodology must provide them with the capability to present the business processes and the related information in order to be used in the improvements of their enterprise operations. Preferably the resulting representations should be reusable eliminating the need of re-mapping the process each time.

During the years in the management consulting business we experienced that all the companies are facing the same problem: none of the people involved really uses their operation manuals as a tool to analyze the operation 
and evaluate the improvements needed to increase the process efficiency, productivity and/or profitability. When a company needs the process mapping or operation manuals the people do not trust the validity of the manuals because they find them never to be up to date and complete.

Therefore, the companies are looking for new ideas in the field of information technology. Standardization is looked at as a way to simplify the process of documentation and to keep it better under control and ISO 9000 is being seen as a standard solution to their needs.

Another problem today is that nobody in the companies is really responsible to maintain the operational procedures. The reason: companies see the subject of operational procedures as being important, but still feel it does have only a rather low priority. We see that many companies assign the responsibility of maintaining the operational procedures to the lowest management level in the organization. On the other hand the companies want more control on their operation in order to increase their market share and their profits.

The use of enterprise models for documenting operational procedures is not really accepted. The main reason is lack of awareness on enterprise integration technology. But even people who do know do not see it yet as a solution to their problem. The available tools and methodologies do not seem to provide the flexibility needed to easily create and maintain the models of their processes.

In the consulting industry the consultants are using tools, but those tools are not really developed to model the enterprise from a user point of view and to cover all the elements (views) needed to capture the enterprise knowledge and to present it to the user. Even more important, such models cannot be maintained by the user themselves, which makes them of no interest for operational use. So, the companies are not using models, but employ mostly common sense as their main tool to make improvements in their operation.

\section{HOW TO INTRODUCE MODELLING TECHNOLOGY}

Introducing enterprise technology to companies in Mexico cannot be done by presenting the contents of know architectures and methodologies (Vernadat, 1996) like ARIS, (http://), CIMOSA (1996) or GERAM (Bernus, et al, 1996) or even the ISO and CEN standards (ISO, 1999 and 2001, Pre EN ISO, 2002). The users in the companies do not understand these technologies and cannot decide on the value for their own organization. Are these just fashions or a trend that should be followed? We must tell them that architectures like CIMOSA cover a hole in the management process that 
presently hinders or at least delays the improvement of their companies. The focus has to be on the hole rather than on the solutions. Why to fill a management process hole? Because there is a need it to see all elements of the enterprise operations prior to make a decision on the improvements. So they need to know that the need a technology that will provide the capability and the How's to capture the knowledge of the operation and will allow its maintaining it as well.

Many of the enterprises do not really understand what it is they are missing, because they do not see the reason nor a convincing application for this technology. Some see it as a methodology to create operational procedures. Also when we tell them that the technology will integrate their company, they do not see what is the different compared with supply chains and some others methodologies identified as integrated methodologies. Many people see ERP as an IT solution to integrate their company.

We have developed a methodology aimed at companies in Mexico to create an understanding for the process modeling and integration technology. Recently, we started to use what we call an "Enterprise Process Architecture" in order to focus the thinking on processes, more than on enterprise integration, because the users understand the term process much better. Thus my clients are now beginning to see what is the reason for this technology. We are telling them that this technology is an Enterprise Process Architecture and it is part of Process Engineering.

\section{THE ENTERPRISE PROCESS ARCHITECTURE}

The concept was developed to support integration of the enterprise. Why named Enterprise Process Architecture (EPA)? Lets look into public definitions (Cambridge, http://):

- Enterprise: an organization, especially a business, or a difficult and important project, one that will earn money. Enterprise is also eagerness to do something new and clever, despite any risks.

- Process: a series of actions or events that are part of a system or a continuing development, or a series of actions that are done to achieve a particular result.

- Architecture: the art and science of designing and making buildings or constructions.

Combining these definitions means we can speak of an enterprise or business as being constructed as a number of business processes producing the things that enable it to earn money and with the business construction guided by an Enterprise Process Architecture (see Fig.1). The Enterprise Process Architecture itself is a suitable collection of available methods and 
tools capable of supporting business process modeling from an operational use perspective.

So the first thing we tell the users is that EPA is a development to cover the big hole in the management process, which exists between the Enterprise Real World (ERW) and the use of Enterprise Technique and Methodology (ETM). Only the use of these techniques and methodologies in a continuous cycle (CLC - Fig. 2) of re-engineering will keep the enterprises competitive, keep their place in their respective markets and open up new ones and will achieve the necessary financial and operational results (FOR). The reengineering has to be guided by QCD - improving product quality, lowering operational costs and shortening delays.

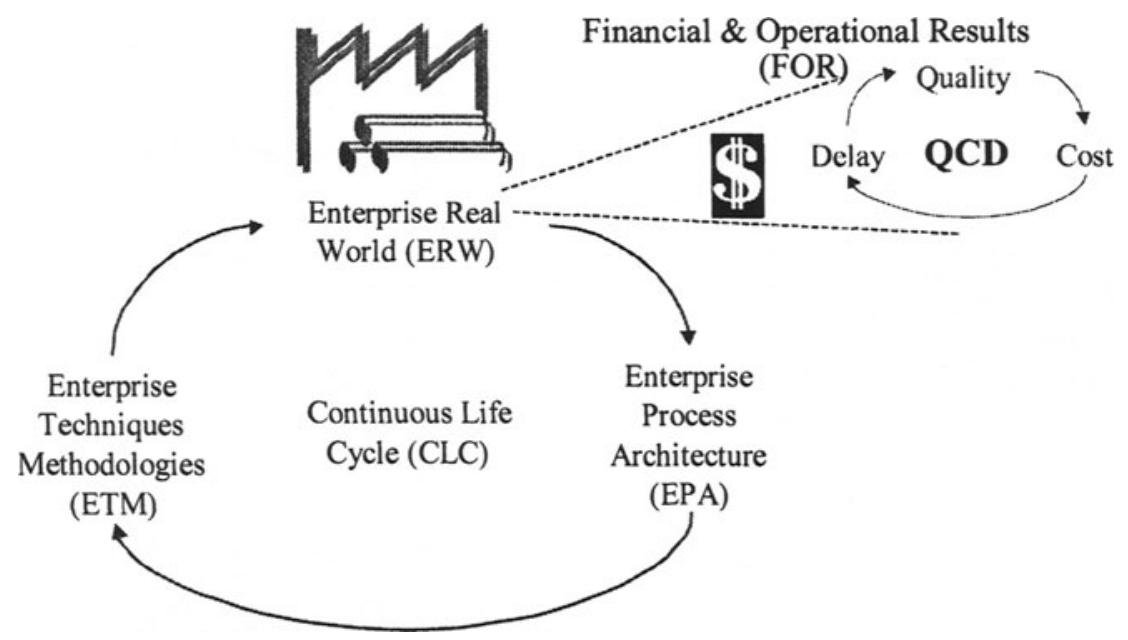

Figure 1: Components and Results of Continuous Re-engineering Process

The final stage in the introduction of EPA is reached when the end user starts to see what the ETM said about their implementation. All of them mention the need to model the Enterprise Processes but none of them really explains how to make an Enterprise Model.

Now if we tell the user that the EPA was made to fill this big management process hole that exist between ERW and ETM they will understand why this technology was developed and will be eager to apply and exploit it.

\subsection{BENEFITS OF THE EPA}

When the users discover the place of the EPA they now will understand the need of the EPA. Now we are in the position to start to explain them the benefits that will come when they create, use and maintain enterprise process models (EPM) with the EPA. 
Some enterprise users instantly start to mention the impact they can have with an EPM. But the concept has to be re-enforced telling them that the three big impact areas to get benefits are: Quality, Cost and Delay. Now we have to document the potential benefits and using these against the old fashioned concepts. In addition, we will create a matrix of the different ETMs needed and how the EPA will support those ETMs.

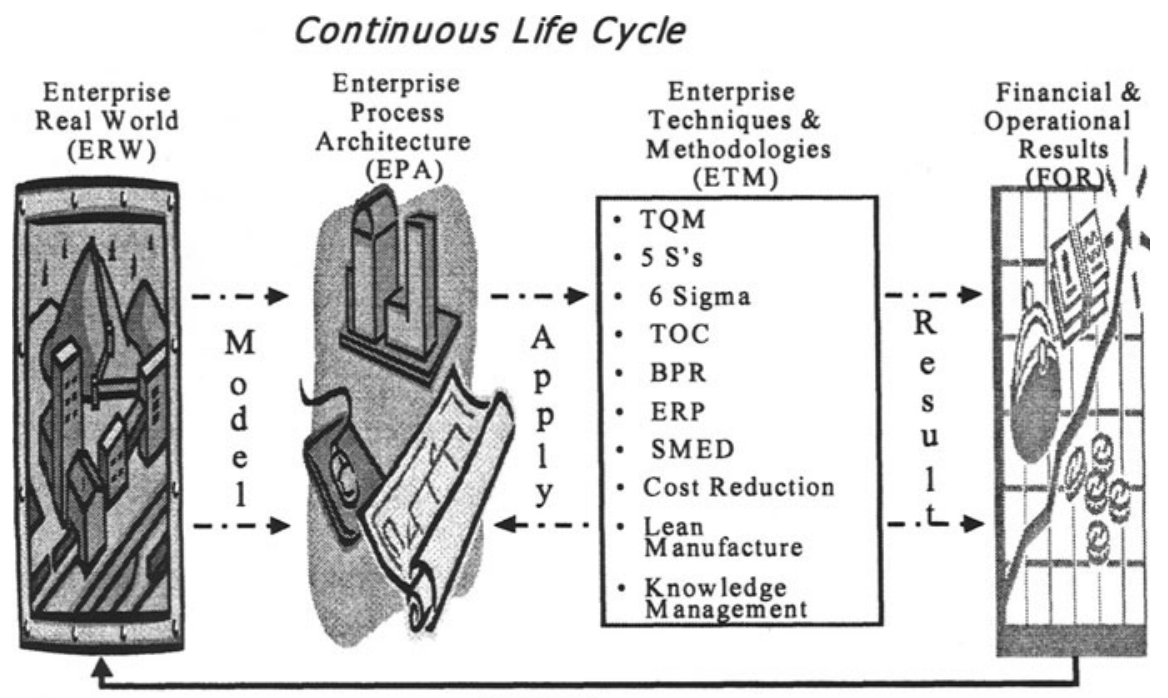

Impact

Figure 2: Continuous Life Cycle Re-engineering Process

\section{CONCLUSION}

In order to create a big response on EPA and EPM from the industry the users have to understand that the EPA has to be positioned between ERW \& ETM. We must tell them that the EPA was made to improve the benefits of the ETM. Finally they will see the need to use all the ARIS or CIMOSA model formalism in order to have a complete Enterprise Model that can be reusable.

The users must have the feeling of not capturing sufficient process knowledge; a lack of knowledge will come if they only model workflows. Also we must create the understanding that Business Process Modeling is not a fashion or new management trend, but is a significant step towards information and knowledge models for decision support in the management of inter-organizational collaborations. 


\section{REFERENCES}

ARIS, http://www.ids-scheer.com/ARIS

P. Bernus, L. Nemes, T.J. Williams (Eds.), (1996), Architectures for Enterprise Integration, The findings of the IFAC/IFIP Task Force, Chapman \& Hall

CIMOSA Association, (1996), CIMOSA - Open System Architecture for CIM, Technical Baseline; Version 3.2, private publication

Cambridge On-Line Dictionaries, http://dictionary.cambridge.org/

Pr EN ISO 19439, (2002), Enterprise Integration - Framework for Enterprise Modelling, CEN TC'310 WG1 together with TC 184 SC5 WG1

Pr EN ISO 19440, (2002), Language Constructs for Enterprise Modelling. CEN TC'310 WGI together with TC 184 SC5 WG1

ISO 14258, (1999), Industrial Automation Systems - Concepts and Rules for Enterprise Models, TC 184 SC5 WG1.

ISO 15704, (2001), Requirements for Enterprise Reference Architecture and Methodologies, TC 184 SC5 WG1.

Vernadat, F.B. (1996), Enterprise Modelling and Integration: Principles and Applications, Chapman \& Hall, London. 